\title{
Technopolitics and participatory processes - Interactions between digital networks and streets in Lisbon
}

\section{SIGRADI2018 TECHNOPOLITICAS xxii congresso da sociedade iberoamericana de gráfica digita 22th conference of the iberoamerican society of digital graphics $07|08| 09 \mid$ novembro|2018 iau usp | são carlos | sp br}

\author{
Ana C. C. Farias \\ ISCTE - Instituto Universitário de Lisboa, ISTAR-IUL| Portugal | carol@sobreurbana.com \\ Alexandra Paio
}

ISCTE - Instituto Universitário de Lisboa, ISTAR-IUL, DINAMIA'CET, VFABLAB| Portugal | alexandra.paio@iscte-iul.pt

\begin{abstract}
This article presents a survey and analysis of the technopolitical devices created in projects of local initiatives carried out in Lisbon, within the scope of the Neighborhoods and Zones of Priority Intervention program, of the City Council. The methodology adopted is based on the reading of the projects, analysis of the technopolitics encountered and interviews with representatives of the entities that proposed them. In this way, it was possible to observe tendencies, potentialities and difficulties faced in the proposal and use of technopolitics in the scope of these projects, which allowed to conclude that the digital dimension has an important role in the reinforcement and expansion of an existing articulation in the territories, between partner entities and communities.
\end{abstract}

Keywords: Technopolitics; Lisbon; observatory; community-based action; digital technology.

\section{INTRODUÇÃO}

As dificuldades de comunicação entre pares e com a população, para os projetos ganharem visibilidade e financiamento (Gadanho, 2017), são algumas das grandes barreiras dos processos participativos contemporâneos assentes na visão de Lefebvre (2016) sobre o direito à cidade. Essas barreiras podem ser mais facilmente transponíveis com as tecnologias digitais, nomeadamente na ampliação do uso da internet e dispositivos mobile, redes sociais, geolocalização, plataformas de crowdsourcing e crowdfunding, no comportamento hacker e na cultura maker (Castells, 2017; Sassen, 2001; Sá, 2015).

Ao uso tático e estratégico destas novas ferramentas digitais, com objetivos de organização e comunicação para a ação coletiva, Toret Medina (2015) e outros autores chamam de tecnopolítica. Os movimentos rebeldes de 2011 - 15M, Primavera Árabe, Occupy Wall Street revelaram as capacidades da auto-organização e articulação política promovidas pelas tecnopolíticas, cuja definição conceitual é apresentada na Figura 1.

Os dispositivos tecnopolíticos propulsores da insurgência política de movimentos rebeldes também estão presentes no cotidiano de vários projetos de base comunitária desenvolvidos nas cidades contemporâneas, a nível mundial. Em Lisboa, mapeamentos coletivos, bancos de trocas, campanhas para financiamento e co criação, são exemplos do uso que iniciativas locais fazem das tecnopolíticas, para moldar a ação e o pensamento coletivos, na criação de redes que se estendem dos meios digitais para os espaços concretos do cotidiano.

Um exemplo é a plataforma Decidimos Lisboa, lançada pela Rede de Desenvolvimento Local de Base Comunitária (DLBC) de Lisboa, para a participação e deliberação de suas entidades associadas. Foi criada a partir do código da plataforma decidim.barcelona, da administração municipal da cidade catalã, disponibilizado na plataforma de códigos abertos GitHub. Com essa ferramenta, lançada em maio de 2018, a Rede DLBC pretende fomentar a participação cívica e dar maior transparência aos processos que gere, entre a definição das demandas das entidades associadas e sua discussão e negociação junto à administração municipal da cidade.

Em Lisboa, as iniciativas locais contam com uma política pública de desenvolvimento local criada em 2011 para "melhorar a qualidade de vida urbana e a coesão territorial" (DMHDL, 2017). Chamado de Bairros e Zonas de Intervenção Prioritária (BIP/ZIP), o programa conta com uma caixa de ferramentas para reabilitar áreas urbanas, composta por: um mapa que define as áreas de intervenção prioritárias; um ciclo anual de financiamento a projetos de iniciativas locais para essas áreas; gabinetes públicos de apoio técnico e burocrático aos projetos; e redes de cooperação que estimulam e fortalecem parcerias entre as várias entidades. A intenção é, cada vez mais, ampliar a participação e garantir sustentabilidade na articulação entre as visões bottom-up (iniciativas de base local) e top-down (administração municipal). 


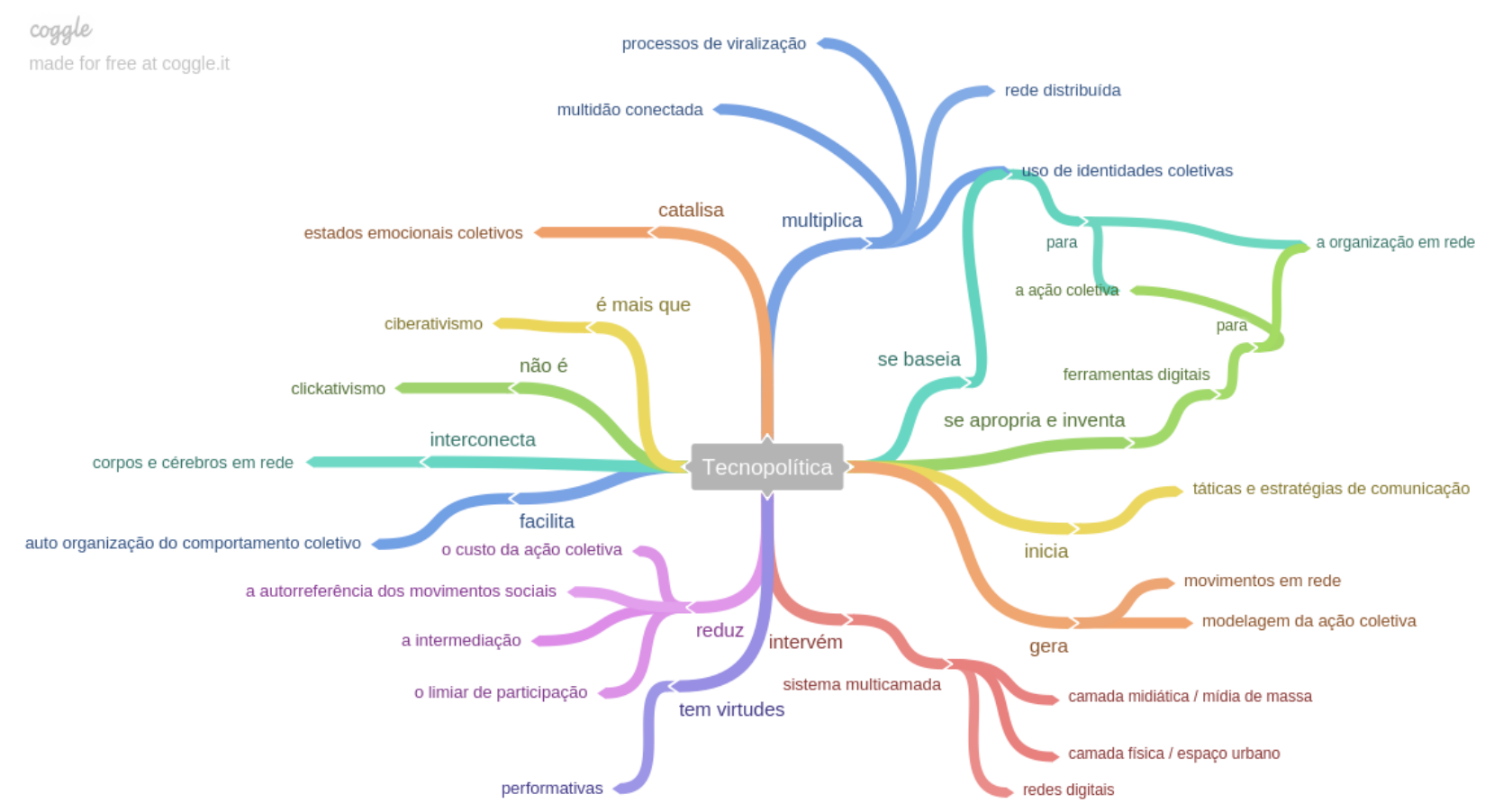

Figura 1: Mapa conceitual da tecnopolítica. Fonte: Adaptado pela autora, a partir de Toret Medina (2015), p. 64. Melhor visualizável em: https://bit.ly/2Ko9KDq

Neste contexto, a investigação em curso está a desenvolver o desenho de um Observatório BIP/ZIP (OBIP/ZIP), ou seja, uma interface digital colaborativa para mediar ações entre a população e a administração local. O O-BIP/ZIP permitirá à cidade de Lisboa ter um dispositivo de observação para acompanhar a evolução dos processos participativos no âmbito do programa BIP/ZIP, no tempo e no espaço, e definir estratégias baseadas em dados e indicadores de previsão.

A pertinência desta investigação reforça-se com as orientações presentes na Agenda 2030 das Nações Unidas para o desenvolvimento sustentável das "cidades e assentamentos humanos inclusivos, seguros, resilientes e sustentáveis" e a necessidade de "planejamento e gerenciamento participativo e integrado". Também os acordos nacionais e supranacionais, no âmbito europeu, para o desenvolvimento sustentável no horizonte 2020, preveem a inovação social e a aplicação das tecnologias de informação e comunicação (TICs) em projetos que visem promover maior coesão social e territorial (Farias, 2018).

Considerando que o desenho de interfaces deve centrarse nas capacidades de as pessoas interagir com tais dispositivos e em suas reais necessidades e expectativas (Baltazar, 2009) (Suchman, 2007), o artigo apresentará o uso de tecnopolíticas nos projetos BIP/ZIP com o objetivo de compreender a experiência de criação e uso desses dispositivos pelos agentes locais, de modo a aproveitá-la no desenho do futuro observatório.

Neste sentido, levantou-se os dispositivos adotados pelos projetos BIP/ZIP, identificou-se as ferramentas utilizadas, analisou-se os objetivos e resultados, e entrevistou-se alguns de seus promotores. Deste modo, foi possível compreender a cultura de uso de tecnopolíticas no contexto específico em estudo, identificando convergências e caminhos a percorrer para o desenho do O-BIP/ZIP. Espera-se, assim, contribuir para 0 fortalecimento e expansão de processos participativos e colaborativos no município de Lisboa.

\section{Metodologia}

A metodologia adotada compreendeu o levantamento, análise e realização de entrevistas. Para o levantamento das tecnopolíticas usadas nos projetos BIP/ZIP, foram utilizadas as fichas de candidaturas, apresentadas nos vários ciclos de financiamento, divulgadas no sítio eletrônico da Câmara Municipal de Lisboa. Foram considerados os projetos realizados entre 2012 e 2017, visto que os dados dos projetos aprovados em 2011 não estão disponíveis, e os projetos aprovados em 2018 ainda estavam no início de suas atividades quando este estudo foi realizado.

Para o levantamento, filtrou-se os projetos através de uma busca pelas palavras-chave: "plataforma", "digital" e "on line". A identificação de tecnopolíticas dentre os diversos dispositivos digitais encontrados foi balizada pelo conceito explorado por Toret Medina (2015) e explicado na Fig. 1, onde as tecnopolíticas definem-se por se orientarem para ações coletivas concretas no espaço urbano, extrapolando as noções de ciberativismo ou clickativismo, e por basearem-se em identidades coletivas, utilizando de ferramentas digitais, com inventividade e performatividade, para a criação de redes e articulação dos propósitos da coletividade.

A análise dos projetos buscou identificar as ferramentas digitais utilizadas, os objetivos que perseguem, resultados encontrados e, ainda, os territórios em que atuam e o tipo de rede que formam (natureza das organizações locais envolvidas). A organização da informação coletada identificou projetos, entidades envolvidas e dispositivos 
utilizados, além de um mapa com a localização, no território da cidade de Lisboa, a ocorrência dessa inovação social.

Por fim, procedeu-se com entrevistas a agentes coordenadores de alguns dos projetos mapeados. As entrevistas questionaram os objetivos do projeto, as redes que pretenderam formar ou reforçar, a escolha das tecnologias utilizadas, a intersecção que o dispositivo criado faz ou fez entre o ambiente digital e o espaço urbano, e a utilização dos dispositivos pelo público-alvo.

Desta forma, pretendeu-se obter, não uma comparação entre os projetos, visto que obedecem a contextos específicos, a capacidades de inovação e uso restritas e direcionadas a suas necessidades e habilidades específicas. O que se pretendeu foi fazer uma reflexão crítica sobre a utilização de tecnopolíticas no âmbito do BIP/ZIP, identificando experiências de articulação em rede auto organizadas pelas coletividades que hoje compõem o sistema em estudo.

\section{Resultados E Discussão}

O levantamento das tecnopolíticas utilizadas nos projetos BIP/ZIP foi feito a partir da triagem e leitura de diversos projetos propostos e realizados entre 2012 e 2017. Os projetos mais antigos, bem como os projetos mais recentes, aprovados no ciclo de financiamento de 2017, apresentaram maior dificuldade para a obtenção de informação; os primeiros, porque vários dos dispositivos digitais criados já não estão mais em utilização e, os últimos, porque ainda não foram finalizados.

A Tabela 1 registra os projetos levantados. Considera-se enquanto tecnopolíticas um total de 13 dispositivos criados por projetos BIP/ZIP, alguns dos quais tiveram desdobramentos e continuidades em mais de um projeto. No ano de 2012, fase inicial do programa, não foi encontrada a proposição de tais dispositivos.

Tabela 1: Projetos BIP/ZIP nos quais foi identificado o uso de tecnopolíticas. Fonte dos dados: Sítio eletrônico da Câmara Municipal de Lisboa: http://bipzip.cm-lisboa.pt/index.htm?l=2017, acessado em 26 jun. 2018.

\begin{tabular}{|c|c|c|}
\hline Ano & Nome Projeto & Endereço Eletrônico \\
\hline \multirow[b]{2}{*}{2017} & $\begin{array}{l}\text { Rede dos Construtores de } \\
\text { Lisboa }\end{array}$ & em construção \\
\hline & Fórum Urbano & $\begin{array}{l}\text { https://www.facebook.com/f } \\
\text { orumurbano/ } \\
\text { http://www.localsapproach. } \\
\text { org/FUNAFA/ }\end{array}$ \\
\hline \multirow{4}{*}{2016} & $\begin{array}{l}\text { C3-Centro Comunitário da } \\
\text { Curraleira }\end{array}$ & $\begin{array}{l}\text { https://novobancocrowdfun } \\
\text { ding.ppl.pt/c3 }\end{array}$ \\
\hline & Muita Fruta & $\begin{array}{l}\text { https://www. muitafruta.org/ } \\
\text { mapamuitafruta/ }\end{array}$ \\
\hline & $\begin{array}{l}\text { Rede de Artes e Ofícios de } \\
\text { Lisboa }\end{array}$ & $\begin{array}{l}\text { https://www.redearteseofici } \\
\text { os.pt/ }\end{array}$ \\
\hline & LXConnect & https://www.Ixconnect.org/ \\
\hline
\end{tabular}

\begin{tabular}{|l|l|l|}
\hline \multirow{2}{*}{2015} & Projecto D'Ajuda & $\underline{\text { http://dajuda.fa.ulisboa.pt/ }}$ \\
\cline { 2 - 3 } & $\begin{array}{l}\text { Construir Redes em } \\
\text { Marvila }\end{array}$ & http://mar-vila.org/ \\
\cline { 2 - 3 } 2014 & Rede Rés-do-Chão & fora do ar \\
\cline { 2 - 3 } & Operação Skyline & http://lisbonskyline.pt/ \\
\cline { 2 - 3 } & DNA Lisboa II & não encontrado \\
\hline \multirow{2}{*}{2013} & Desenhar Redes & Rede de Carpintarias de \\
Lisboa & http://mar-vila.org/ \\
\hline
\end{tabular}

Table 1: Levantamento de tecnopolíticas em projetos BIP/ZIP

A Fig. 2 traz a Carta BIP/ZIP - mapa de Lisboa com os territórios prioritários marcados em azul - com o realce em vermelho dos territórios sobre os quais foram encontrados os dispositivos tecnopolíticos pesquisados. A ilustração desconsidera o projeto Fórum Urbano, que propõe atuação em todos os territórios. Desta forma, percebe-se uma maior incidência dos dispositivos nos territórios mais centrais (toda a zona histórica é atendida) e uma dispersão / ausência nas zonas periféricas.

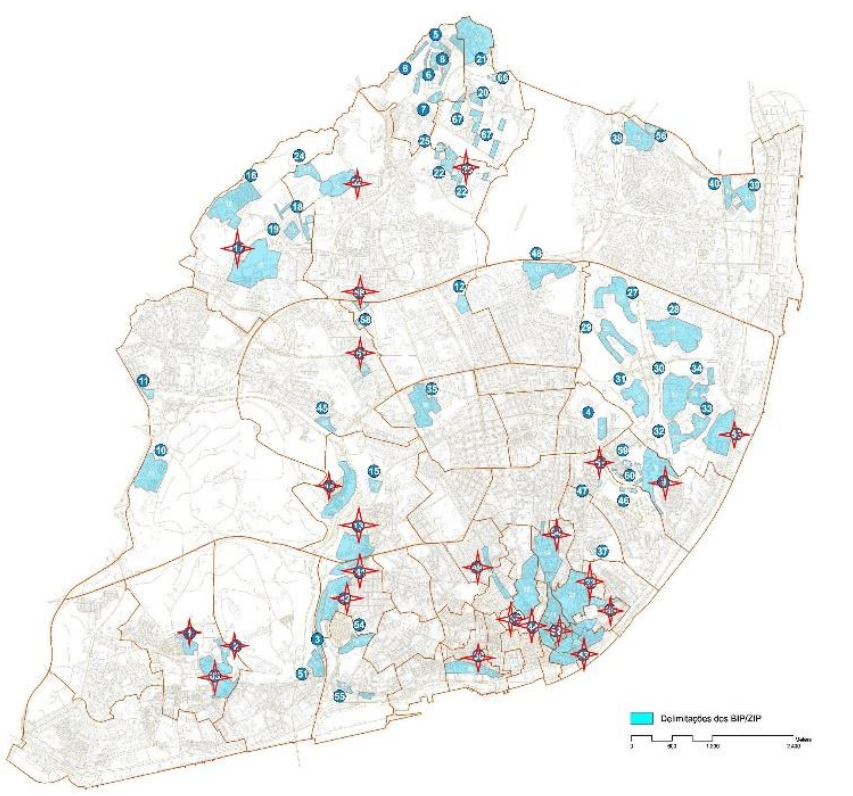

Figura 2: Carta BIP/ZIP com identificação, em vermelho, dos territórios de ocorrência dos dispositivos tecnopolíticos. Fonte da Carta: sítio eletrônico da Câmara Municipal de Lisboa <https://bit.ly/2IGWRUX. Adaptada pelos autores>.

Foram identificadas 55 entidades e grupos informais dentre os promotores e parceiros dos projetos mapeados. A Figura 3 traz uma ilustração das redes de colaboração formadas entre eles. Os projetos estão representados pelos ícones na cor preto e as entidades, categorizadas por sua composição, representadas pelas diferentes cores. As dez categorias de entidades identificadas são: Ateliês ou associações de arquitetos e urbanistas, Entidades de comerciantes ou prestadores de serviço, 
Entidades de ensino ou investigação, Junta de Freguesia, Entidade cultural, Associação de moradores e de bairro, Entidade filantrópica, Entidade pró esportes, Grupo informal e Entidade de ação social.

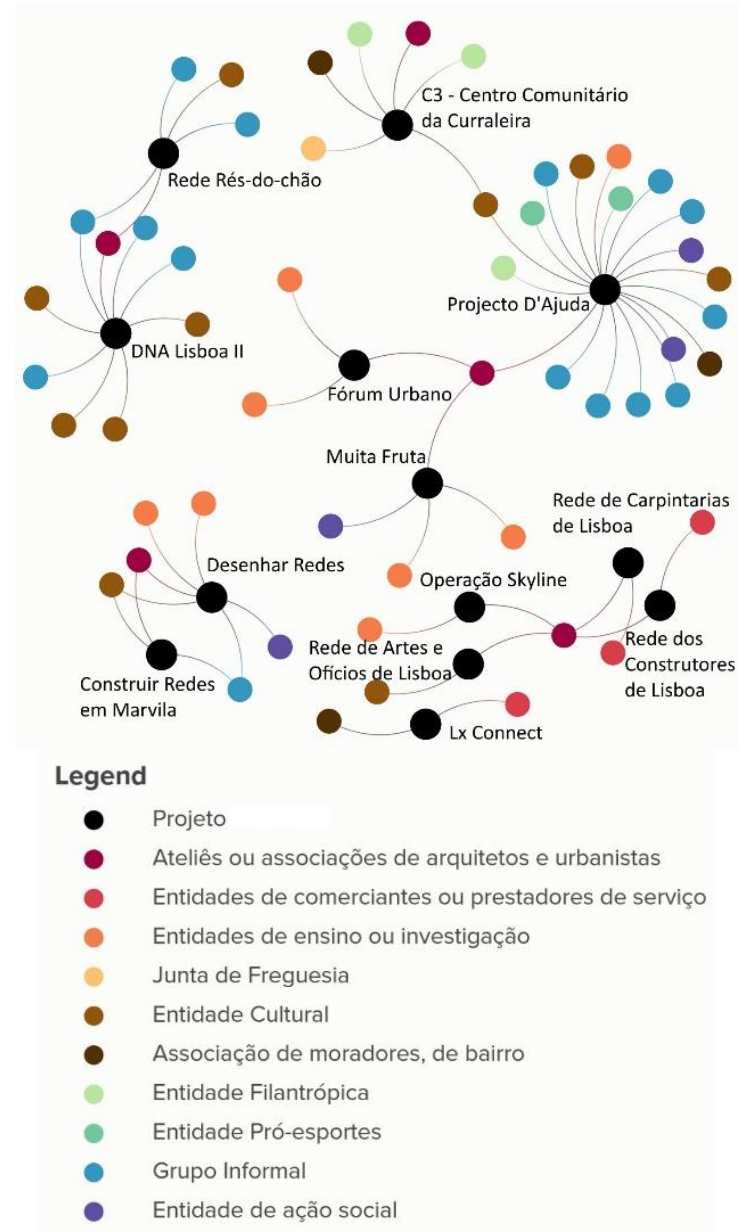

Figura 3: Redes formadas entre entidades promotoras e entidades parceiras nos projetos BIP/ZIP que utilizaram de dispositivos tecnopolíticos. Fonte: Ilustração gerada pela autora através da plataforma kumu.io. Melhor visualizável em: https://bit.ly/2MEbLtx. Informações obtidas no sítio eletrônico da Câmara Municipal de Lisboa: http://bipzip.cmlisboa.pt/index.htm?l=2017

A ilustração da Fig. 3 permite observar a atuação de algumas entidades em mais de um projeto, revelando a tendência natural para a formação de redes entre eles. Dentre os pesquisados, somente um, o LXConnect, está totalmente desconectado dos demais, em relação às parcerias formadas entre as entidades. O Projecto D'Ajuda é o que tem a maior rede de entidades e os projetos Desenhar Redes e Construir Redes em Marvila são os que têm maior número de entidades conectadas a outros projetos. Também é possível observar na Fig. 3 a predominância de entidades do tipo 'Grupos Informais', categoria de coletividade permitida a atuar nos projetos BIP/ZIP como parceira. O tipo de entidade menos frequente nesta amostra coletada é Junta de Freguesia.

Relativamente às ferramentas, os dispositivos encontrados utilizam de sites interativos e intuitivos para o alojamento de mapeamentos colaborativos, vídeos, fotografias, manuais e campanhas específicas. O único a desenvolver uma aplicação para smartphones (disponível para IOS e
Android) foi o projeto LXConnect, do Centro Social da Musgueira, que propõe uma rede para oferta e pedidos de bens e serviços entre entidades locais. Serviço também acessível por computadores.

O projeto C3-Centro Comunitário da Curraleira é o único, dentre os pesquisados, que utilizou de financiamento coletivo, como parte das atividades pactuadas no BIP/ZIP. O objetivo do financiamento coletivo, que obteve sucesso, foi arrecadar recursos para as instalações do centro comunitário, através da plataforma Novo Banco Crowdfunding.

Para além das atividades pactuadas com o BIP/ZIP, a entidade Rés-do-Chão também já utilizou de financiamento coletivo, tendo como objetivo a construção de um parklet. Já no âmbito do programa, a associação mantém a Plataforma Rés-do-Chão (inclusive em parceria no projeto DNA Lisboa II), que mapeia imóveis vazios no nível térreo dos edifícios, identifica seus proprietários e cria uma rede de serviços entre comerciantes, artistas, moradores etc. para divulgar as atividades do bairro. A intenção da entidade é contribuir para a vitalidade das ruas a partir da reocupação temporária dos imóveis. Inicialmente instalados e atuantes no território BIP/ZIP noㅡ 50 (Misericórdia), agora dedicam-se aos territórios $\mathrm{n}^{\circ} \mathbf{3 0}$, 32 e 33, todos na região de Marvila. No entanto, durante a realização deste estudo, o sítio eletrônico da plataforma Rés-do-Chão esteve fora do ar, impossibilitando a análise de suas ferramentas.

O projeto Muita Fruta propõe um mapeamento colaborativo das árvores frutíferas nos logradouros urbanos da cidade. Utiliza a base do OpenStreetMap e a plataforma Lealeft para a programação do mapa. Lançado em 2017, ainda tem poucas inserções.

Projecto D'Ajuda, Desenhar Redes e Construir Redes em Marvila tem em comum o foco nas dinâmicas de bairros específicos. O Projecto D’Ajuda, continuação do projeto 2 de Maio Todos os Dias, de 2013, atuou na região da Ajuda com o objetivo de promover e qualificar o território para a melhoria da qualidade de vida de seus habitantes. Dentre as várias atividades realizadas (incluindo auscultação da comunidade, formação, criação de uma marca para o bairro e dinamização de espaços públicos), lançou o Observatório D'Ajuda, que consiste na elaboração de um diagnóstico participado da região, para a articulação futura de micro intervenções que venham ao encontro das observações e ideias levantadas. Alojado no sítio eletrônico do projeto, o observatório recolhe as ideias através da plataforma Your Priorities (uma aplicação para eDemocracy da Citizens Foundation <https://citizens.is/>), mapeadas pelo Google Maps. Tendo suas atividades financiadas pelo BIP/ZIP finalizadas em 2016, datam daí as últimas inserções na plataforma.

Em Marvila, os projetos Desenhar e Construir Redes trabalharam a sensibilização da população residente para as problemáticas do espaço público e da gentrificação, atual ameaça ao território de Marvila Velha. Para tanto, criaram um sítio eletrônico onde depositaram todo o conteúdo produzido tais como mapeamentos, ensaios fotográficos, arquivos de documentos históricos, desenhos, vídeos, registros das intervenções urbanas realizadas e da exposição final. Mais do que um sítio 
eletrônico convencional, a plataforma Mar-Vila pretende ser uma ferramenta educativa, tendo sua alimentação e gestão realizadas de forma colaborativa com a comunidade local, acumulando e partilhando informações pertinentes às estratégias anti-gentrificação.

Paralelamente à gentrificação - em sentido de causa e efeito - o fenômeno da requalificação urbana também é assunto em pauta na cidade de Lisboa, atualmente. Com o intuito de visibilizar saberes tradicionais necessários para que a requalificação em curso respeite o patrimônio material e imaterial da cidade, o atelier de arquitetura Artéria tem estado a articular três redes através de projetos BIP/ZIP: Rede de Carpintarias, Rede de Artes e Ofícios e Rede de Construtores de Lisboa. Os três projetos compreendem o mapeamento de oficinas e atores e a construção de redes através da produção de conteúdo sobre os temas e elementos mapeados, disponibilizados em plataformas próprias (A Rede de Construtores tem sua plataforma ainda em construção).

Como parte da estratégia para ampliar e fortalecer as redes, também são promovidas rodas de conversa e ações de formação. A Figura 4 traz o registro do primeiro encontro do Ciclo de Conversas Cidade Estaleiro, da Rede de Construtores de Lisboa. Já a Rede de Carpintarias promoveu, dentre outras atividades, um concurso de ideias de trabalhos entre estudantes e oficinas mapeadas; e a Rede de Artes e Ofícios, cuja inserção na plataforma é colaborativa e continua em aberto, promoveu a realização de estágios profissionais nas oficinas mapeadas.

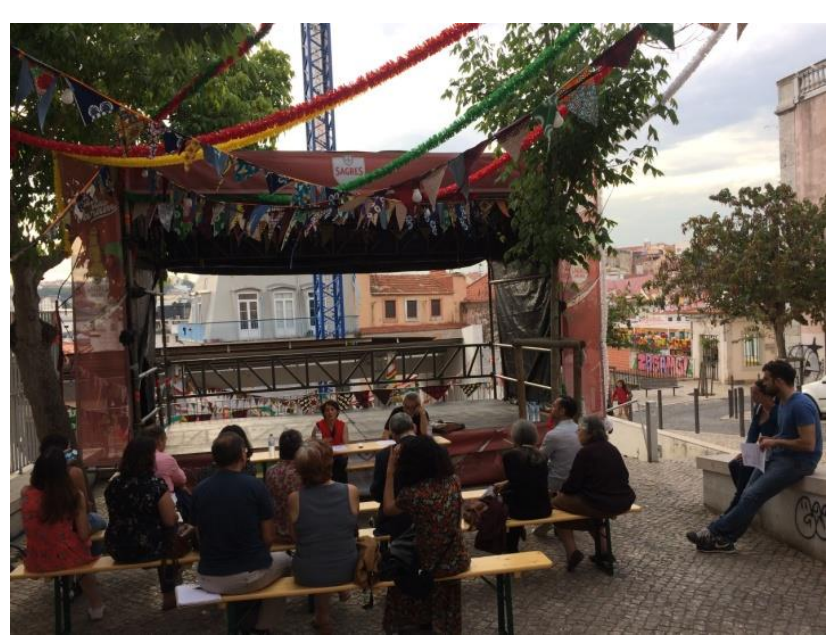

Figura 4: Encontro \#1 do Ciclo de Conversas Cidade Estaleiro do projeto Rede de Construtores de Lisboa, realizado no dia 20 de Jun. 2018 no Largo da Rosa. Fonte: Da autora.

Outro projeto realizado pelo atelier Artéria, a Operação Skyline busca reativar as coberturas dos edifícios da cidade, apresentando para tal uma solução arquitetônica, jurídica e ambiental. O projeto, inserido na representação portuguesa da Biennale di Venezia 2014, dispõe de um sítio eletrônico que recebe inserções voluntárias de 'condomínios' e 'investidores', disponibilizando seus imóveis ou demonstrando interesse em investir, respectivamente. Também apresenta o arranjo proposto, de forma detalhada, antecipando as questões mais frequentes e disponibilizando manuais para participação, um voltado para os 'condomínios' e outro para os 'investidores'. Acreditam estar a promover a cidadania ativa e a valorização das coberturas enquanto recurso disponível na cidade e capazes de Ihes trazer retornos sociais, econômicos e ambientais.

Por fim, o projeto Fórum Urbano, aprovado no ciclo de 2017 e, portanto, ainda em execução, propõe a criação de uma plataforma, com 'existência' digital e física, reunindo de forma colaborativa e disponibilizando informações sobre os projetos BIP/ZIP. A versão digital da plataforma é prevista como um motor de busca aos vários projetos, organizados por categorias e disponibilizados em fichas descritivas. Também deverá conter testemunhos de 'agentes transformadores', imagens com 'antes/depois' das intervenções urbanas realizadas, 'espaço BIP/ZIP Júnior', fóruns de discussões, portal de trocas, contatos e redes do universo BIP/ZIP. Prevê ainda integração com um blog colaborativo, canal no Youtube e redes sociais (Facebook, Instagram, Twitter). Em elaboração, deverá ser lançada até outubro de 2018. Já a existência física da plataforma compreende a realização de workshops, assembleias abertas realizadas nos bairros e uma exposição itinerante sobre os projetos BIP/ZIP.

\section{ENTREVISTAS}

Partindo dessa análise inicial dos projetos, buscou-se conhecer um pouco melhor alguns deles, através da realização de entrevistas com representantes das entidades envolvidas. Foram entrevistados representantes de seis projetos: C3-Centro Comunitário da Curraleira, Fórum Urbano, Rede de Carpintarias, Rede de Artes e Ofícios, Rede de Construtores, Operação Skyline.

$\mathrm{Na}$ entrevista com um representante do Clube Intercultural Europeu, promotor do projeto C3-Centro Comunitário da Curraleira, foi esclarecido que a reforma do imóvel previsto para receber as instalações do Espaço C3 objetivo específico do projeto - demandaria um investimento maior que o projeto poderia custear. A opção pelo financiamento coletivo se deu, então, por entenderem que se tratava de uma 'causa coletiva' - a construção de um espaço coworking 'solidário' voltado para pequenas empresas e ONGs.

Para a campanha, foram realizadas várias atividades no bairro, envolvendo a comunidade como forma de aumentar o apelo da 'causa'. No entanto, as contribuições financeiras vieram principalmente das redes das entidades promotoras e parceiras, especialmente de colaboradores do Clube Intercultural Europeu, como ex-estudantes intercambistas, muitos dos quais vivem hoje em outros países.

A escolha da plataforma utilizada - Novo Banco Cowdfunding - deu-se pelo fato de se tratar do banco do qual o Clube Intercultural Europeu é cliente e, também, porque a plataforma oferece uma contribuição a mais aos projetos que atingirem a meta de suas campanhas. Depois dessa primeira experiência exitosa, o Clube considera a possibilidade de fazer nova campanha de financiamento coletivo para terminar as instalações do Espaço C3, ainda incompletas, através da mesma plataforma.

$\mathrm{Na}$ entrevista com uma representante do projeto Fórum Urbano, foi esclarecido que o projeto se assenta na ausência de informação sobre os vários projetos já realizados no âmbito do BIP/ZIP e na ideia de que a

5 
sistematização desta informação poderá ajudar na criação, ampliação e fortalecimento de redes de colaboração. Nesse sentido, o projeto fornecerá um sítio eletrônico com informação disponível a partir de pesquisa por múltiplos critérios. A plataforma trará o mapeamento dos projetos realizados, informação detalhada sobre eles agentes, temáticas, metodologias, atividades realizadas etc. - e um manual que agregará as boas práticas identificadas, resultando num guia para o desenvolvimento local em Lisboa. Fora do ambiente digital, o projeto também articula momentos de festa, workshops, discussão e uma exposição itinerante. Espera-se, com essa articulação, compartilhar experiências e modos de fazer, fomentando parcerias entre entidades e projetos.

$\mathrm{Na}$ entrevista com uma das arquitetas do atelier Artéria, falou-se sobre os quatro projetos do atelier mapeados neste estudo: Rede de Carpintarias, Rede de Artes e Ofícios, Rede de Construtores e Operação Skyline. A arquiteta esclareceu que a necessidade de $\mathrm{O}$ atelier fomentar tais redes decorre do contexto no qual ele foi criado, o momento da grande crise econômica de 2011. Instalado no centro da cidade com o objetivo de fazer projetos e obras de reabilitação, o atelier começa suas atividades a desenvolver trabalhos críticos ao modelo de reabilitação urbana em curso em Lisboa enxergando, nas plataformas digitais, a possibilidade de melhor compreender seu território de ação, de estudar, classificar, dissecar determinadas matérias de interesse, articulando as escalas micro e macro da cidade.

Para realizar obras é preciso ter à disposição toda uma rede de serviços que engloba algumas atividades em processo de expulsão do centro da cidade, profissões ainda sem regulação e profissionais em fim de carreira e sem aprendizes. Dessa conclusão, esclareceu a entrevistada, surgiu a ideia da Rede de Carpintarias, desdobrando-se nas outras redes criadas posteriormente. Para a primeira delas foi feito um minucioso mapeamento de práticas de trabalho, utilizando métodos da antropologia, com uma pesquisa muito centrada nas pessoas. Pela quantidade reduzida de oficinas, foi possível mapear todas elas, cuja pesquisa está disponível na plataforma através de um mapa estático.

$\mathrm{Na}$ Rede de Artes e Ofícios utilizou-se de métodos mais simplificados para mapear os espaços das oficinas. Pela diversidade de artífices e serviços, optou-se por um mapeamento que pudesse ser expandido de forma colaborativa, aberto ainda hoje para a inserção voluntária de oficinas e mestres.

A Rede de Construtores, mais ampla, mais complexa e mais próxima da atuação do atelier, vai abranger todas as profissões, levantar dados estatísticos, dados do terreno e revelará dados aparentemente ocultos, para formar um caldo crítico em relação à reabilitação atualmente praticada em Lisboa. O recorte temporal da pesquisa é o presente, mapeando obras realizadas entre 2017 e 2018.

A Operação Skyline, apesar da repercussão midiática do projeto, o atelier considera-o malsucedido, pela dificuldade que teve de conseguir adesões à rede. Sugerem que esse tipo de plataforma, pelo potencial de inovação na gestão do uso do solo, deveria ser promovida e articulada por outro tipo de entidade, em especial, a administração municipal. Ainda assim, houve interação na plataforma proposta pela Artéria e ainda há projetos em vias de concretização.

Finalmente, considera-se, com a análise feita até aqui, que foi possível perceber tendências, potencialidades e dificuldades encontradas pelos projetos, na proposição de seus dispositivos tecnopolíticos.

\section{Considerações Finais}

$\mathrm{O}$ trabalho realizado permite concluir que as tecnologias digitais, nos projetos BIP/ZIP, são ferramentas de apoio à ação das entidades, que buscam dar respostas a necessidades práticas como o acesso a um espaço físico de trabalho ou o mapeamento dos atores e recursos das redes laborais em que estão envolvidos. A dimensão digital tem importante papel, portanto, no reforço e expansão de uma articulação que já é feita nos territórios, entre entidades parceiras e comunidades.

A maioria dos dispositivos tecnopolíticos aqui encontrados refere-se a ferramentas para troca de bens e serviços, construção de redes laborais, organização de informação útil para a elaboração de projetos, adequação de espaços físicos para trabalho, ou seja, enquadrados em temáticas econômicas. O que é compatível com as estratégias lançadas pelo BIP/ZIP para o desenvolvimento local, que compreendem, dentre outras coisas, a formação de competências e a geração de emprego. Tais estratégias estão amarradas em diversos acordos nacionais e supranacionais que influenciam o BIP/ZIP, como forma de promover a coesão sócio territorial (Farias, 2018).

Outra premissa básica do BIP/ZIP é a aposta na formação de redes de colaboração (DMHDL, 2017). Observa-se, nos dispositivos tecnopolíticos criados, que há a necessidade e a intenção, dentre as iniciativas locais, de criar e ampliar redes de solidariedade e cooperação. Nesse sentido, a tecnologia digital e a cultura de rede (Castells, 2017) são combinadas em práticas que articulam uma cidade mais inclusiva e aberta a uma cidadania ativa, ingredientes essenciais na reivindicação do direito à cidade (Lefebvre, 2016). No entanto, a utilização dos dispositivos tecnopolíticos e a ação em rede tem, no contexto deste estudo, um longo caminho de aprendizagens à frente.

A criação de sites e páginas em redes sociais, bem como o desenvolvimento de inovação social, são itens integrantes das fichas de candidatura para 0 financiamento do BIP/ZIP, o que tende a incentivar que os projetos os proponham. No entanto, os dispositivos encontrados não demonstram grande performance, nem todos estão associados a páginas em redes sociais e os que estão também não demonstraram viralidade em suas campanhas. Como os projetos tem cronograma de realização de um ano, passado esse período as entidades enfrentam maior dificuldade para manter as plataformas em funcionamento, mesmo quando trata-se somente da manutenção de um sítio eletrônico.

Outra questão observada em relação ao uso de tecnologias digitais refere-se à dificuldade, não só de manutenção dos dispositivos criados, mas também de uso, por parte de alguns grupos como pessoas mais 
idosas ou aquelas com menor acesso às tecnologias. Um exemplo é a plataforma para partilha de recursos, criada pela Clip Recursos e Desenvolvimento, uma associação de entidades não governamentais, empresas e pessoas que atua na capacitação de indivíduos e coletividades para o desenvolvimento local. A plataforma copiava o código aberto da plataforma Ciclos, mas segundo uma representante da Clip, não atendia às necessidades da associação e gerava dificuldades de uso para os associados. Com o tempo, a plataforma foi deixada de lado e as trocas, que contam com uma moeda social virtual, passaram a ser articuladas através de um grupo no Facebook, lista de e-mails e telefone.

Ainda assim, a prática de trocas de serviços e bens promovida pela Clip inspirou a Junta de Freguesia de Campolide a propor o mesmo à sua comunidade, através do projeto $R e$ (viver) o Bairro, desenvolvido no ciclo do financiamento de 2017 do BIP/ZIP. No entanto, optaram pela não utilização de dispositivo tecnológico para mediar as trocas, considerando os hábitos e capacidades dos integrantes de sua rede.

Assim como estes projetos, vários outros acabam por se restringirem a ferramentas mais simplificadas, já familiares ao público-alvo, o que revela a necessidade de melhor desenhar os dispositivos, atendendo às limitações iniciais dos usuários. Como remarcaram alguns entrevistados, o uso das tecnopolíticas não pode ser um empecilho, mas ao contrário, tem que ser um facilitador para a articulação das pessoas e entidades envolvidas.

Considera-se, por fim, que as observações retiradas desse estudo têm importante contribuição para a elaboração do Observatório BIP/ZIP.

\section{AGRADECIMENTOS}

Agradecemos a colaboração dos entrevistados pelo fornecimento de informações a esta pesquisa. Igualmente, agradecemos o apoio da ISTA-Escola de Tecnologias e Arquitetura, pela bolsa de mérito $3^{\circ}$ ciclo que suporta a investigação de doutoramento da autora Ana C. C. Farias, intitulada 'Observatório BIP/ZIP: Mediações digitais para o desenvolvimento local em Lisboa', da qual este artigo é peça integrante.

\section{REFERÊNCIAS}

Baltazar, A. P. (2009). Cyberarchitecture: the virtualisation of architecture beyond representation towards interactivity. London: Bartlett School of Architecture.

Castells, M. (2017). A Sociedade em Rede. 18 ${ }^{\mathrm{a}}$ ed. São Paulo: Paz e Terra.

Departamento Municipal de Habitação e Desenvolvimento Local (DMHDL) (2017). Good Practice Summary - Lisbon Local Development Strategy for Neighbourhoods or Areas of Priority Intervention (BIP/ZIP): an integrated toolbox. CML. Recuperado de: http://urbact.eu/in.

Farias, A. C. C. (2018). Top-down + bottom-up: Interações políticas na cidade de Lisboa por meio do programa BIP/ZIP. Artigo apresentado à Third International Conference of Young Urban Researchers (TICYUrb). Lisboa: ISCTE-IUL.

Gadanho, P. (2017). Entrevista concedida em 11 jul. 2017. In: BARATTO, Romullo. Urbanismo tático, utopias e curadoria ativista: uma entrevista com Pedro Gadanho. 02 Nov 2017. ArchDaily Brasil. Recuperado de https://www.archdaily.com.br/br/882682/urbanismo-taticoutopias-e-curadoria-ativista-uma-entrevista-com-pedrogadanho

Lefebvre, H. (2016). O direito à cidade. Itapevi, SP: Nebli.

Sá, A. I. de. (2015). Urbanismo entre pares - cidade e tecnopolítica. Dissertação (Mestrado em Arquitetura e Urbanismo) Escola de Arquitetura da Universidade Federal de Minas Gerais, Belo Horizonte.

Sassen, S. (2001). The Global City. Princeton: Princeton University Press.

Suchman, L. A. (2007). Human-machine reconfigurations. Plans and situated actions. New York: Cambridge Press.

Toret Medina, J. (coord.) (2015). Tecnopolítica Y 15M: La potencia de las multitudes conectadas. Un estudio sobre la gestación y explosión del 15M. Barcelona: UOC Ediciones. 